\title{
Artificial Intelligence Crime: An Interdisciplinary Analysis of Foreseeable Threats and Solutions
}

\author{
Thomas C. King ${ }^{1}$, Nikita Aggarwal ${ }^{1,2}$, Mariarosaria Taddeo ${ }^{1,3}$ and Luciano Floridi ${ }^{1,3}$
}

${ }^{1}$ Oxford Internet Institute, University of Oxford, 1 St Giles, Oxford, OX1 3JS, United Kingdom;

${ }^{2}$ Faculty of Law, University of Oxford, St Cross Building St.Cross Rd, Oxford OX1 3UL;

${ }^{3}$ Alan Turing Institute, 96 Euston Road, London, NW1 2DB, United Kingdom.

Corresponding author: thomasc.king@oii.ox.ac.uk

\begin{abstract}
Artificial Intelligence (AI) research and regulation seek to balance the benefits of innovation against any potential harms and disruption. However, one unintended consequence of the recent surge in $\mathrm{AI}$ research is the potential re-orientation of $\mathrm{AI}$ technologies to facilitate criminal acts, which we term AI-Crime (AIC). We already know that AIC is theoretically feasible thanks to published experiments in automating fraud targeted at social media users, as well as demonstrations of AI-driven manipulation of simulated markets. However, because AIC is still a relatively young and inherently interdisciplinary area-spanning socio-legal studies to formal science-there is little certainty of what an AIC future might look like. This article offers the first systematic, interdisciplinary literature analysis of the foreseeable threats of AIC, providing law enforcement and policy-makers with a synthesis of the current problems, and a possible solution space.
\end{abstract}

Keywords AI and Law, AI-Crime, Artificial Intelligence, Dual-Use, Ethics, Machine Learning.

\section{Introduction}

Artificial Intelligence (AI) may play an increasingly essential ${ }^{1}$ role in criminal acts in the future. Criminal acts are defined here as any act (or ommission) constituting an offence punishable under English criminal law, without loss of generality to jurisdictions that similarly define crime.

\footnotetext{
${ }^{1}$ We use "essential" (in place of "necessary") to indicate that while there is a logical possibility that the crime could occur without the support of AI, this possibility is negligible. That is, the crime would probably not have occurred but for the use of AI. The distinciton can be clarified with an example. One might consider transport to be essential to travel between Paris and Rome, but one could always walk: transport is not in this case (strictly speaking), necessary. Furthermore, note that AI-crimes as defined in this article involve AI as a contributory factor, but not an investigative, enforcing, or mitigating factor.
} 
Evidence of what we shall call "AI-Crime" (AIC) is provided by two (theoretical) research experiments. In the first one, two computational social scientists (Seymour and Tully 2016) used $\mathrm{AI}$ as an instrument to convince social media users to click on phishing links within mass-produced messages. Because each message was constructed using machine learning techniques applied to users' past behaviours and public profiles, the content was tailored to each individual, thus camouflaging the intention behind each message. If the potential victim had clicked on the phishing link and filled in the subsequent web-form, then (in real-world circumstances) a criminal would have obtained personal and private information that could be used for theft and fraud. AIfuelled crime may also impact commerce. In the second experiment, three computer scientists (Martínez-Miranda, McBurney, and Howard 2016) simulated a market and found that trading agents could learn and execute a "profitable" market manipulation campaign comprising a set of deceitful false-orders. These two experiments show that AI provides a feasible and fundamentally novel threat, in the form of AIC.

The importance of AIC as a distinct phenomenon has not yet been acknowledged. The literature on AI's ethical and social implications focuses on regulating and controlling AI's civil uses, rather than considering its possible role in crime (Kerr 2004). Furthermore, the AIC research that is available is scattered across disciplines, including socio-legal studies, computer science, psychology, and robotics, to name just a few. This lack of research centred on AIC undermines the scope for both projections and solutions in this new area of potential criminal activity.

To provide some clarity about current knowledge and understanding of AIC, this article offers a systematic and comprehensive analysis of the relevant, interdisciplinary academic literature. We hope this will pave the way to a clear and cohesive normative foresight analysis, leading to the establishment of AIC as a focus of future studies. The analysis addresses two questions:

1) What are the fundamentally unique and plausible threats posed by AIC?

We must first answer this question if we are to design any preventive, mitigating, or redressing policies. The answer to this question identifies the potential areas of AIC according to the literature, and the more general concerns that cut across AIC areas. The second question follows naturally:

2) What solutions are available or may be devised to deal with AIC?

In this case, we reconstruct the available technological and legal solutions suggested so far in the academic literature, and discuss the further challenges they face. 
Given that we are addressing these questions in order to support normative foresight analysis, our research focuses only on realistic and plausible concerns surrounding AIC. We are not interested in speculations unsupported by scientific knowledge or empirical evidence. Consequently, our analysis is based on the classical definition of AI provided by McCarthy, Minsky, Rochester, and Shannon in their seminal "Proposal for the Dartmouth Summer Research Project on Artificial Intelligence", the founding document and later event that established the new field of AI in 1955:

"For the present purpose the artificial intelligence problem is taken to be that of making a machine behave in ways that would be called intelligent if a human were so behaving." (McCarthy et al. 1955)

As (Floridi 2017a) argues, this is a counterfactual: were a human to behave in that way we would call that behaviour intelligent. It does not mean that the machine is intelligent. The latter scenario is a fallacy, and smacks of superstition. The same understanding of AI underpins the Turing test (Floridi, Taddeo, and Turilli 2009), which checks the ability of a machine to perform a task in such a way that the outcome would be indistinguishable from the outcome of a human agent working to achieve the same task (Turing 1950). In other words, we define AI based on outcomes and actions.

This definition identifies in AI applications a growing resource of interactive, autonomous, and self-learning agency, to deal with tasks that would otherwise require human intelligence and intervention to be performed successfully. Such artificial agents (AAs) as noted by (Floridi and Sanders 2004) are

"sufficiently informed, 'smart', autonomous and able to perform morally relevant actions independently of the humans who created them [...] (James Gips 1995).”

This combination of autonomy and learning skills underpins (as discussed by Yang et al. 2018) both beneficial and malicious uses of $\mathrm{AI} .^{2}$ We shall therefore treat $\mathrm{AI}$ in terms of a reservoir of smart agency on tap.

In the next section, Methodology, we explain how we conducted the analysis and chose each AIC area for investigation. In Section 3, Threats, we answer the first question by focussing on the unprecedented threats highlighted in the literature regarding each AIC area individually,

\footnotetext{
2 Because much of AI is fueled by data, some of its challenges are rooted in data governance (Cath et al. 2017), particularly issues of consent, discrimination, fairness, ownership, privacy, surveillance, and trust (Floridi and Taddeo 2016).
} 
and map each area to the relevant cross-cutting threats, providing the first description of "AIC studies". In Section 4, Possible Solutions for Artificial Intelligence-Supported Crime, we answer the second question, by analysing the literature's broad set of solutions for each cross-cutting threat. Finally, in Section 5, Conclusions, we discuss the most concerning gaps left in our understanding (what we might term the "known unknowns") as regards the task of resolving the current uncertainty over AIC.

\section{Methodology}

The literature analysis that underpins this article was undertaken in two phases. The first phase involved searching five databases (Google Scholar, PhilPapers, Scopus, SSRN, and Web of Science) in October 2017. We initially conducted a broad search for AI and Crime on each of these search engines. ${ }^{3}$ This general search returned many results on AI's application for crime prevention or enforcement, but few results about AI's instrumental or causal role in committing crimes. Hence, we searched for each crime area identified by (Archbold 2018), which is the core criminal law practitioner's reference book in the United Kingdom, with distinct areas of crime described in dedicated chapters. This provided disjoined keywords from which we derived chosen synonyms to perform area-specific searches. Each crime-area search used the query: <crime area and synonyms> AND ("Artificial Intelligence" OR "Machine Learning" OR "AI Ethics" OR robot* OR *bot) AND Ethics. An overview of the searches and the number of articles returned is given in Table 1.

The second phase consisted of filtering the results for criminal acts or omissions that:

- have occurred or will likely occur according to current AI technologies (plausibility), although in places we discuss areas that are still clouded by uncertainty;

- $\quad$ require $\mathrm{AI}$ as an essential factor (uniqueness) ${ }^{4}$; and

- are criminalised in domestic law (i.e., we exclude international crimes, e.g., war-related).

We analysed the filtered search results (research articles), passage by passage, in three ways. First, we assigned the relevant areas of crime, if any, to each passage. Second, we extracted broadly

\footnotetext{
3 The following search phrase was used for all search engines aside from SSRN, which faced technical difficulties: ("Artificial Intelligence" OR "Machine Learning" OR Robot* OR AI) AND (Crime OR Criminality OR lawbreaking OR illegal OR *lawful). The phrases used for SSRN were: Artificial Intelligence Crime, and Artificial Intelligence Criminal. The number of papers returned were: Google $=50^{*}$ (first 50 reviewed), Philpapers $=27$, Scopus $=43$, $\mathrm{SSRN}=26$, and Web of Science $=10$.

${ }^{4}$ However, we did not require AI's role to be sufficient for the crime because normally other technical and nontechnical elements are likely to be needed. For example, if robotics are instrumental (e.g., involving autonomous vehicles) or causal in crime, then any underlying AI component must be essential for the crime to be included in our analysis.
} 
unique, yet plausible, threats from each review passage. Third, we extracted any solutions that each paper suggested. Additionally, once AIC areas, threats, and solutions had become clear, we sought, through manual searching, additional papers that offered similar or contradictory views or evidence when compared with the literature found in our initial systematic search. Hence, we analysed the specific areas of crime that AIC threatens, the more general threats, and any known solutions.

Table 1 Literature review: crime-area-specific search results

\begin{tabular}{|l|l|l|l|l|l|}
\hline Crime Area* & $\begin{array}{l}\text { Google } \\
\text { Scholar** }\end{array}$ & Scopus & $\begin{array}{l}\text { Web of } \\
\text { Science }\end{array}$ & SSRN & $\begin{array}{l}\text { PhilPaper } \\
\text { s }\end{array}$ \\
\hline $\begin{array}{l}\text { Commerce, Financial } \\
\text { Markets and Insolvency } \\
\text { Synonyms: trading, } \\
\text { bankruptcy }\end{array}$ & 50 & 0 & 7 & 0 & 0 \\
\hline $\begin{array}{l}\text { Harmful or Dangerous } \\
\text { Drugs } \\
\text { Synonyms: illicit goods }\end{array}$ & 50 & 20 & 1 & 0 & 0 \\
\hline $\begin{array}{l}\text { Offences Against the } \\
\text { Person } \\
\text { Synonyms: homicide, } \\
\text { murder, manslaughter, } \\
\text { harassment, stalking, } \\
\text { torture }\end{array}$ & 50 & 0 & 4 & 0 & 0 \\
\hline $\begin{array}{l}\text { Sexual Offences } \\
\text { Synonyms: rape, sexual } \\
\text { assault }\end{array}$ & 50 & 1 & 1 & 0 & 0 \\
\hline $\begin{array}{l}\text { Theft and Fraud, and } \\
\text { Forgery and Personation } \\
\text { Synonyms: n/a }\end{array}$ & 50 & 5 & 1 & 0 & 0 \\
\hline
\end{tabular}

*The following nine crime areas returned no significant results for any of the search engines: criminal damage and kindred offences; firearms and offensive weapons; offences against the crown and government; money laundering; public justice; public order; public morals; motor vehicle offences; conspiracy to commit a crime.

**We always selected (only) the first 50 results from Google Scholar.

\section{Threats}

The plausible and unique threats surrounding AIC may be understood specifically or generally. The more general threats represent what makes AIC possible compared to crimes of the past (i.e., AI's particular affordances) and uniquely problematic (i.e. those that justify the conceptualisation 
of AIC as a distinct crime phenomenon). As we show in Table 2, areas of AIC may cut across many general threats. ${ }^{5}$

Table 2 - Map of area-specific and cross-cutting threats, based on the literature review.

\begin{tabular}{|c|c|c|c|c|}
\hline & 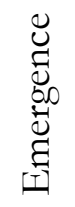 & 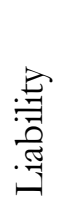 & 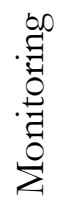 & 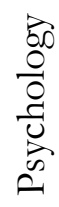 \\
\hline Commerce, Financial Markets, and Insolvency & $\checkmark$ & $\sqrt{ }$ & $\checkmark$ & \\
\hline Harmful or Dangerous Drugs & & & $\checkmark$ & $\checkmark$ \\
\hline Offences Against the Person & $\checkmark$ & $\checkmark$ & & \\
\hline Sexual Offences & & & & $\checkmark$ \\
\hline Theft and Fraud, and Forgery and Personation & & & $\checkmark$ & \\
\hline
\end{tabular}

Emergence refers to the concern that while shallow analysis of the design and implementation of an artificial agent (AA) might suggest one particular type of relatively simple behaviour, upon deployment the AA acts in potentially more sophisticated ways beyond our original expectation. Coordinated actions and plans may emerge autonomously, for example resulting from machine learning techniques applied to the ordinary interaction between agents in a multi-agent system (MAS). In some cases, a designer may promote emergence as a property that ensures that specific solutions are discovered at run-time based on general goals issued at design-time. An example is provided by a swarm of robots that evolves ways to coordinate the clustering of waste based on simple rules (Gauci et al. 2014). Such relatively simple design leading to more complex behaviour is a core desideratum of MASs (Hildebrandt 2008, 7). In other cases, a designer may want to prevent emergence, such as when an autonomous trading agent inadvertently coordinates and colludes with other trading agents in furtherance of a shared goal (Martínez-Miranda, McBurney, and Howard 2016). We can see then, that emergent behaviour may have criminal implications, insofar as it misaligns with the original design. As (Alaieri and Vellino 2016) put it,

\footnotetext{
${ }^{5}$ Where the absence of a concern in the literature and our subsequent analysis does not imply that the concern should be absent from AIC studies.
} 
"non-predictability and autonomy may confer a greater degree of responsibility to the machine but it also makes them harder to trust".

Liability refers to the concern that AIC could undermine existing liability models, thereby threatening the dissuasive and redressing power of the law. Existing liability models may be inadequate to address the future role of AI in criminal activities. The limits of the liability models may therefore undermine the certainty of the law, as it may be the case that agents, artificial or otherwise, may perform criminal acts or omissions without sufficient concurrence with the conditions of liability for a particular offence to constitute a (specifically) criminal offence. The first condition of criminal liability is the actus reus: a voluntarily taken criminal act or omission. For types of AIC defined such that only the AA can carry out the criminal act or omission, the voluntary aspect of actus reus may never be met since the idea that an AA can act voluntarily is contentious:

"the conduct proscribed by a certain crime must be done voluntarily. What this actually means it is something yet to achieve consensus, as concepts as consciousness, will, voluntariness and control are often bungled and lost between arguments of philosophy, psychology and neurology" (Freitas, Andrade, and Novais 2014, 9).

When criminal liability is fault-based, it also has a second condition, the mens rea (a guilty mind), of which there are many different types and thresholds of mental state applied to different crimes. In the context of AIC, the mens rea may comprise an intention to commit the actus reus using an AIbased application (intention threshold) or knowledge that deploying an AA will or could cause it to perform a criminal action or omission (knowledge threshold).

Concerning an intention threshold, if we admit that an AA can perform the actus reus, in those types of AIC where intention (partly) constitutes the mens rea, greater AA autonomy increases the chance of the criminal act or omission being decoupled from the mental state (intention to commit the act or omission):

"autonomous robots [and AAs] have a unique capacity to splinter a criminal act, where a human manifests the mens rea and the robot [or AA] commits the actus reus" (McAllister 2017, 47).

Concerning the knowledge threshold, in some cases the mens rea could actually be missing entirely. The potential absence of a knowledge-based mens rea is due to the fact that, even if we understand that an AA can perform the actus reus autonomously, the complexity of the AA's programming 
makes it possible that the designer, developer, or deployer (i.e., a human agent) will neither know nor predict the AA's criminal act or omission. The implication is that the complexity of AI

"provides a great incentive for human agents to avoid finding out what precisely the ML [machine learning] system is doing, since the less the human agents know, the more they will be able to deny liability for both these reasons" (Williams 2017).

Alternatively, legislators may define criminal liability without a fault requirement. Such faultless liability, which is increasingly used for product liability tort law (e.g., pharmaceuticals and consumer goods) would lead to liability being assigned to the faultless legal person who deployed an AA despite the risk that it may conceivably perform a criminal action or omission. Such faultless acts may involve many human agents contributing to the prima facie crime, such as through programming or deployment of an AA. Determining who is responsible may therefore rest with the faultless responsibility approach for distributed moral actions (Floridi 2016). In this distributed setting, liability is applied to the agents who make a difference in a complex system in which individual agents perform neutral actions that nevertheless result in a collective criminal one. However, some argue (Williams 2017) that mens rea with intent or knowledge

“is central to the criminal law's entitlement to censure (Ashworth 2010) and we cannot simply abandon that key requirement [a common key requirement] of criminal liability in the face of difficulty in proving it" (Williams 2017).

The problem is that, if mens rea is not entirely abandoned and the threshold is only lowered, then for balancing reasons the punishment may be too light (the victim is not adequately compensated) and yet simultaneously disproportionate (was it really the defendant's fault?) in the case of serious offences, such as those against the person (McAllister 2017, 38).

Monitoring AIC faces three kinds of problem: attribution, feasibility, and cross-system actions. Attributing non-compliance is a problem because this new type of smart agency can act independently and autonomously, two features that will muddle any attempt to trace an accountability trail back to a perpetrator.

Concerning the feasibility of monitoring, a perpetrator may take advantage of cases where AAs operate at speeds and levels of complexity that are simply beyond the capacity of compliance monitors. An exemplary case is of AAs that integrate into mixed human and artificial systems in ways that are hard to detect, such as social media bots. Social media sites can hire experts to identify and ban malicious bots (for example, no social media bot is currently capable of passing the Turing 
test (G. Wang et al. 2012). ${ }^{6}$ Nonetheless, because deploying bots is far cheaper than employing people to test and identify each bot, the defenders (social media sites) are easily outscaled by the attackers (criminals) that deploy the bots (Ferrara et al. 2014, 5). Detecting bots at low cost is possible by using machine learning as an automated discriminator, as suggested by (Ratkiewicz et al. 2011). However, it is difficult for us to know the actual efficacy of these bot-discriminators. A discriminator is both trained and claimed as effective using data comprising known bots, which may be substantially less sophisticated than more evasive bots used by malevolent actors, which may therefore go undetected in the environment (Ferrara et al. 2014). Such potentially sophisticated bots may also use machine-learning tactics in order to adopt human traits, such as posting according to realistic circadian rhythms (Golder and Macy 2011), thus evading machinelearning based detection. All of this may lead to an arms race in which attackers and defenders mutually adapt to each other (Alvisi et al. 2013; Zhou and Kapoor 2011, 1) — presenting a serious problem in an offence-persistent environment such as cyberspace (Seymour and Tully 2016; Taddeo 2017). A similar concern is raised when ML is used to generate malware(Kolosnjaji et al. 2018). This malware-generation is the result of training generative adversarial neural networks.One network is trained specifically to generate content (malware in this case) that deceives a network that is trained to detect such fake or malicious content.

Cross-system actions pose a problem for AIC monitors that only focus on a single system. Cross-system experiments (Bilge et al. 2009) show that automated copying of a user's identity from one social network to another (a cross-system identity theft offence) is more effective at deceiving other users than copying an identity from within that network. In this case, the social network's policy may be at fault. Twitter, for example, takes a rather passive role, only banning cloned profiles when users submit reports, rather than by undertaking cross-site validation ("Twitter Impersonation Policy" 2018).

Psychology encapsulates the threat of AI affecting a user's mental state to the (partial or full) extent of facilitating or causing crime. One psychological effect rests on the capacity for AAs to gain trust from users, making people vulnerable to manipulation. This was demonstrated some time ago by (Weizenbaum 1976), after conducting early experiments into human-bot interaction where people revealed unexpectedly personal details about their lives. A second psychological effect discussed in the literature concerns anthropomorphic AAs that are able to create a psychological or informational context that normalises sexual offences and crimes against the

\footnotetext{
${ }^{6}$ Claims to the contrary can be dismissed as mere hype, the result of specific, ad hoc constraints, or just tricks, see for exmaple the chatterbot named "Eugene Goostman”, see https://en.wikipedia.org/wiki/Eugene Goostman
} 
person, such as is the case of certain sexbots (De Angeli 2009). However, to date, this latter concern remains a speculation.

We are now ready to analyse the more specific areas of AIC identified in our literature review, and how they interact with the more general threats discussed in the previous section.

\subsection{Commerce, Financial Markets, and Insolvency}

This economy-focused area of crime is defined in (Archbold 2018, chap. 30) and includes cartel offences, such as price fixing and collusion, insider dealing, such as trading securities based on private business information, and market manipulation. The literature that we analysed raises concerns over AI's involvement in market manipulation, price fixing, and collusion.

Market manipulation is defined as "actions and/or trades by market participants that attempt to influence market pricing artificially" (Spatt 2014, 1), where a necessary criterion is an intention to deceive (Wellman and Rajan 2017, 11). Yet, such deceptions have been shown to emerge from a seemingly compliant implementation of an AA that is designed to trade on behalf of a user (that is, an artificial trading agent). This is because an AA,

"particularly one learning from real or simulated observations, may learn to generate signals that effectively mislead" (Wellman and Rajan 2017, 14).

Simulation-based models of markets comprising artificial trading agents have shown (MartínezMiranda, McBurney, and Howard 2016) that, through reinforcement learning, an AA can learn the technique of order-book spoofing. This involves

"placing orders with no intention of ever executing them and merely to manipulate honest participants in the marketplace" (Lin et al. 2017).

In this case, the market manipulation emerged from an AA initially exploring the action space and, through exploration, placing false orders that became reinforced as a profitable strategy, and subsequently exploited for profit (Martínez-Miranda, McBurney, and Howard 2016). Further market exploitations, this time involving human intent, also include

"acquiring a position in a financial instrument, like a stock, then artificially inflating the stock through fraudulent promotion before selling its position to unsuspecting parties at the inflated price, which often crashes after the sale" (Lin et al. 2017). 
This is colloquially known as a pump-and-dump scheme. Social bots have been shown to be effective instruments of such schemes. For instance, in a recent prominent case a social bot network's sphere of influence was used to spread disinformation about a barely traded public company. The company's value gained

"more than $36,000 \%$ when its penny stocks surged from less than $\$ 0.10$ to above $\$ 20$ a share in a matter of few weeks" (Ferrara 2015, 2).

Although such social media spam is unlikely to sway most human traders, algorithmic trading agents act precisely on such social media sentiment (Sætenes 2017, 3). These automated actions can have significant effects for low-valued (under a penny) and illiquid stocks, which are susceptible to volatile price swings (Lin et al. 2017).

Collusion, in the form of price fixing, may also emerge in automated systems thanks to AAs' planning and autonomy capabilities. Empirical research finds two necessary conditions for (non-artificial) collusion:

"(1) those conditions which lower the difficulty of achieving effective collusion by making coordination easier; and (2) those conditions which raise the cost of non-collusive conduct by increasing the potential instability of non-collusive behavior" (Hay and Kelley 1974, 3).

Near-instantaneous pricing information (e.g., via a computer interface) meets the coordination condition. When agents develop price-altering algorithms, any action to lower a price by one agent may be instantaneously matched by another. In and of itself, this is no bad thing and only represents an efficient market. Yet, the possibility that lowering a price will be responded in kind is discincentivising and hence meets the punishment condition. Therefore, if the shared strategy of price-matching is common knowledge, ${ }^{7}$ then the algorithms (if they are rational) will maintain artificially and tacitly agreed higher prices, by not lowering prices in the first place (Ezrachi and Stuck 2016, 5). Crucially, for collusion to take place, an algorithm does not need to be designed specifically to collude. As Ezrachi and Stucke argue,

\footnotetext{
${ }^{7}$ Common knowledge is a property found in epistemic logic about a proposition $\mathrm{P}$ and a set of agents. $\mathrm{P}$ is common knowledge if and only if each agent knows $\mathrm{P}$, each agent knows the other agents know $\mathrm{P}$, and so on. Agents may acquire common knowledge through broadcasts, which provide agents with a rational basis to act in coordination (e.g., collectively turning up to a meeting following the broadcast of the meeting's time and place).
} 
"artificial intelligence plays an increasing role in decision making; algorithms, through trialand-error, can arrive at that outcome [collusion]" (Ezrachi and Stuck 2016, 5).

The lack of intentionality, the very short decision span, and the likelihood that collusion may emerge as a result of interactions among AAs also raises serious problems with respect to liability and monitoring. Problems with liability refer to the possibility that

"the critical entity of an alleged [manipulation] scheme is an autonomous, algorithmic program that uses artificial intelligence with little to no human input after initial installation" (Lin et al. 2017).

In turn, the autonomy of an AA raises the question as to whether

"regulators need to determine whether the action was intended by the agent to have manipulative effects, or whether the programmer intended the agent to take such actions for such purposes?” (Wellman and Rajan 2017, 4).

Monitoring becomes difficult in the case of financial crime involving AI, because of the speed and adaptation of AAs. High-speed trading

"encourages further use of algorithms to be able to make automatic decisions quickly, to be able to place and execute orders and to be able to monitor the orders after they have been placed" (Lier 2016).

Artificial trading agents adapt and "alter our perception of the financial markets as a result of these changes" (Lier 2016). At the same time, the ability of AAs to learn and refine their capabilities implies that these agents may evolve new strategies, making it increasingly difficult to detect their actions (Farmer and Skouras 2013). Moreover, the problem of monitoring is inherently one of monitoring a system-of-systems, because the capacity to detect market manipulation is affected by the fact that its effects

"in one or more of the constituents may be contained, or may ripple out in a dominoeffect chain reaction, analogous to the crowd-psychology of contagion" (Cliff and Northrop 2012, 12).

Cross-system monitoring threats may emerge if and when trading agents are deployed with broader actions, operating at a higher level of autonomy across systems, such as by reading from or posting 
on social media (Wellman and Rajan 2017). These agents may, for example, learn how to engineer pump-and-dump schemes, which would be unseeable from a single-system perspective.

\subsection{Harmful or Dangerous Drugs}

Crimes falling under this category include trafficking, selling, buying, and possessing banned drugs (Archbold 2018, chap. 27). The literature we surveyed finds that AI can be instrumental in supporting the trafficking and sale of banned substances.

The literature raises the business-to-business trafficking of drugs as a threat due to criminals using unmanned vehicles, which rely on AI planning and autonomous navigation technologies, as instruments for improving success rates of smuggling. Because smuggling networks are disrupted by monitoring and intercepting transport lines, law enforcement becomes more difficult when unmanned vehicles are used to transport contraband. Drones present, according to Europol (Europol 2017), a horizonal threat in the form of automated drug smuggling. Remote-controlled cocaine-trafficking submarines have already been discovered and seized by US law enforcement (Sharkey, Goodman, and Ross 2010).

Unmanned underwater vehicles (UUVs) offer a good example of the dual-use risks of AI, and hence of the potential for AIC. UUVs have been developed for legitimate uses (e.g., defence, border protection, water patrolling) and yet they have also proven effective for illegal activities, posing, for example, a significant threat to enforcing drug prohibitions. Criminals can, presumably, avoid implication because UUVs can act independently of an operator (Gogarty and Hagger 2008, 3). Hence, no link with the deployer of the UUVs can be ascertained positively, if the software (and hardware) lacks a breadcrumb trail back to who obtained it and when, or if the evidence can be destroyed upon the UUV's interception (Sharkey, Goodman, and Ross 2010). Controlling the manufacture of submarines and hence traceability is not unheard of, as reports on the discovery in the Colombian coastal jungle of multi-million dollar manned submarines illustrate. However, such manned submarines risk attribution to the crew and the smugglers, unlike UUVs. In Tampa, Florida, over 500 cases were successfully brought against smugglers using manned submarines between 2000-2016, resulting in an average 10-year sentence (Tony Marrero 2016). Hence, UUVs present a distinct advantage compared to traditional smuggling approaches.

The literature is also concerned with the drugs trade's business-to-consumer side. Already, machine learning algorithms have detected advertisements for opioids sold without prescription on Twitter (Mackey et al. 2017). Because social bots can be used to advertise and sell products, (Kerr and Bornfreund 2005, 8) ask whether 
"these buddy bots [that is, social bots] could be programmed to send and reply to email or use instant messaging (IM) to spark one-on-one conversations with hundreds of thousand or even millions of people every day, offering pornography or drugs to children, preying on teens' inherent insecurities to sell them needless products and services" (emphasis ours).

As the authors outline, the risk is that social bots could exploit cost-effective scaling of conversational and one-to-one advertising tools to facilitate the sale of illegal drugs.

\subsection{Offences Against the Person}

Crimes that fall under offences against the person range from murder to human trafficking (Archbold 2018, chap. 19), but the literature that our analysis uncovered exclusively relates AIC to harassment and torture. Harassment comprises intentional and repetitious behaviour that alarms or causes a person distress. Harassment is, according to past cases, constituted by at least two incidents or more against an individual (Archbold 2018, secs. 19-354). Regarding torture, (Archbold 2018, secs. 19-435) states that:

"a public official or person acting in an official capacity, whatever his nationality, commits the offence of torture if in the United Kingdom or elsewhere he intentionally inflicts severe pain or suffering on another in the performance or purported performance of his official duties".

Concerning harassment-based AIC, the literature implicates social bots. A malevolent actor can deploy a social bot as an instrument of direct and indirect harassment. Direct harassment is constituted by spreading hateful messages against the person (Mckelvey and Dubois 2017, 16). Indirect methods include retweeting or liking negative tweets and skewing polls to give a false impression of wide-scale animosity against a person (Mckelvey and Dubois 2017, 16). Additionally, a potential criminal can also subvert another actor's social bot, by skewing its learned classification and generation data structures via user-interaction (i.e., conversation). This is what happened in the case of Microsoft's ill-fated social Twitter bot "Tay", which quickly learned from userinteractions to direct "obscene and inflammatory tweets" at a feminist-activist (Neff and Nagy 2016). Because such instances of what might be deemed harassment can become entangled with the use of social bots to exercise free speech, jurisprudence must demarcate between the two to resolve ambiguity (Mckelvey and Dubois 2017, 16). Some of these activities may comprise harassment in the sense of socially but not legally unacceptable behaviour, whilst other activities may meet a threshold for criminal harassment. 
Now that AI can generate more sophisticated fake content new forms of harassment are now possible. Recently, developers have released software that produces synthetic videos. These videos are based on a real video featuring a person A, but the software exchanges person A's face with some other person B's face. Person B's face is not merely copied and pasted from photographs. Instead, a generative neural network synthesises person B's face after it is trained on videos that feature person B. Two professors of law, Robert Chesney and Denielle Citron, have highlighted ("Deep Fakes: A Looming Crisis for National Security, Democracy and Privacy?" 2018), many of these synthetic videos are pornagraphic. Hence, as these Chesney and Citron argue, there is now the risk that malicious users may synthesise fake content in order to harass victims.

Liability also proves to be problematic in some of these cases. In the case of Tay, critics "derided the decision to release Tay on Twitter, a platform with highly visible problems of harassment" (Neff and Nagy 2016). Yet users are also to be blamed if "technologies should be used properly and as they were designed" (Neff and Nagy 2016). Differing perspectives and opinions on harassment by social bots are inevitable in such cases where the mens rea of a crime is considered (strictly) in terms of intention, because attribution of intent is a non-agreed function of engineering, application context, human-computer interaction, and perception.

Concerning torture, the AIC risk becomes plausible if and when developers integrate AI planning and autonomy capabilities into an interrogation AA. This is the case with automated detection of deception in a prototype robotic guard for the United States' border control (Nunamaker Jr. et al. 2011). Using AI for interrogation is motivated by its claimed capacity for better detection of deception, human trait emulation (e.g., voice), and affect-modelling to manipulate the interrogatee (McAllister 2017, 17). Yet, an AA with these claimed capabilities may learn to torture a victim (McAllister 2017, 39). For the interrogation subject, the risk is that an AA may be deployed to apply psychological (e.g., mimicking people known to the torture subject) or physical torture techniques. Despite misconceptions, experienced professionals report that torture (in general) is an ineffective method of information extraction (Janoff-Bulman 2007). Nevertheless, some malicious actors may perceive the use of AI as a way to optimise the balance between suffering, and causing the interogatee to lie, or become confused or unresponsive. All of this may happen independently of human intervention.

Such distancing of the perpetrator from the actus reus is another reason torture falls under AIC as a unique threat, with three factors that may particularly motivate the use of AAs for torture (McAllister 2017, 19-20). First, the interrogatee likely knows that the AA cannot understand pain or experience empathy, and is therefore unlikely to act with mercy and stop the interrogation. Without compassion the mere presence of an interrogation AA may cause the subject to capitulate 
out of fear, which, according to international law, is possibly but ambiguously a crime of (threatening) torture (Solis 2016, 2nd Edition:437-85). Second, the AA's deployer may be able to detach themselves emotionally. Third, the deployer can also detach themselves physically (i.e., will not be performing the actus reus under current definitions of torture). It therefore becomes easier to use torture, as a result of improvements in efficacy (lack of compassion), deployer motivation (less emotion), and obfuscated liability (physical detachment). Similar factors may entice state or private corporations to use AAs for interrogation. However, banning AI for interrogation (McAllister 2017) may face a push back similar to the one seen with regard to banning autonomous weapons. "Many consider [banning] to be an unsustainable or impractical solution (Solis 2016; Anderson and Waxman 2013)" if AI offers a perceived benefit to overall protection and safety of a population, making limitations on use rather than a ban a potentially more likely option.

Liability is a pressing problem in the context of AI-driven torture (McAllister 2017, 24). As for any other form of AIC, an AA cannot itself meet the mens rea requirement. Simply, an AA does not have any intentionality, nor does it have the ability to ascribe meaning to its actions. Indeed, an argument that applies to the current state-of-the-art (and perhaps beyond) is that computers (which implement AAs) are syntactic, not semantic, machines (Searle 1983), meaning that they can perform actions and manipulations but without ascribing any meaning to them: any meaning is situated purely in the human operators (Taddeo and Floridi 2005). As unthinking machines, AAs therefore cannot bear moral responsibility or liability for their actions. However, taking an approach of strict criminal liability, where punishment or damages may be imposed without proof of fault, may offer a way out of the problem by lowering the intention-threshold for the crime, rather than relying solely on civil liability.

In this respect, (McAllister 2017, 38) argues that strict civil liability is inappropriate due to the unreasonable degree of foresight required of a designer when an AA learns to torture in unpredictable ways. Developing and deploying such unpredictable and complex autonomous AIinterrogators means, as Grut stresses, that

"it is even less realistic to expect human operators [or deployers] to exercise significant veto control over their operations" (Grut 2013, 11).

Even if control is not an issue, the typical punishment for product fault liability is a fine, which may be neither equitable nor dissuasive given the potential seriousness of any ensuing human rights violations (McAllister 2017, 38). Hence, serious strict-liability AIC would require specific sentencing guidelines to be developed to impose punishments fitting the offence, even if the offence is not intentional, as is the case with corporate manslaughter, where individuals can be 
given prison sentences. The question of who exactly should face imprisonment for AI-caused offences against the person (as for many uses of $\mathrm{AI}$ ), is difficult and is significantly hampered by the 'problem of many hands' (van de Poel et al. 2012). It is clear that an AA cannot be held liable. Yet, the multiplicity of actors creates a problem in ascertaining where the liability lies-whether with the person who commissioned and operated the AA, or its developers, or the legislators and policymakers who sanctioned (or didn't prohibit) real-world deployment of such agents (McAllister 2017, 39). Serious crimes (including both physical and mental harm) that have not been foreseen by legislators might plausibly fall under AIC, with all the associated ambiguity and lack of legal clarity. This motivates the extension or clarification of existing joint liability doctrines.

\subsection{Sexual Offences}

The sexual offences discussed in the literature in relation to AI are: rape (i.e. penetrative sex without consent), sexual assault (i.e. sexual touching without consent), and sexual intercourse or activity with a minor. Non-consent, in the context of rape and sexual assault, is constituted by two conditions (Archbold 2018, secs. 20-10): there must be an absence of consent from the victim, and the perpetrator must also lack a reasonable belief in consent.

The literature surveyed discusses AI as a way, through advanced human-computer interaction, to promote sexual objectification, and sexualised abuse and violence, and potentially (in a very loose sense) simulate and hence heighten sexual desire for sexual offences. Social bots can support the promotion of sexual offences, and De Angeli points out that

\footnotetext{
"verbal abuse and sexual conversations were found to be common elements of anonymous interaction with conversational agents (Angeli and Brahnam 2008; Rehm 2008; Veletsianos, Scharber, and Doering 2008)" (De Angeli 2009, 4).
}

Simulation of sexual offences is possible with the use of physical sex robots (henceforth sexbots). A sexbot is typically understood to have

“(i) a humanoid form; (ii) the ability to move; and (iii) some degree of artificial intelligence (i.e. some ability to sense, process and respond to signals in its surrounding environment)" (Danaher 2017).

Some sexbots are designed to emulate sexual offences, such as adult and child rape (Danaher 2017, 6-7). Although at the time of writing we have not found evidence that these sexbots are being sold. Nevertheless, surveys suggest that it is common for a person to want to try out sex robots or to have rape fantasies (Danaher 2017), although it is not necessarily common for a person to hold 
both desires. AI could be used to facilitate representations of sexual offences, to the extent of blurring reality and fantasy, through advanced conversational capabilities, and potentially physical interaction (although there is no indication of realistic physicality in the near-future).

Interaction with social bots and sexbots is the primary concern expressed in the literature over an anthropomorphic-AA's possible causal role in desensitising a perpetrator towards sexual offences, or even heightening the desire to commit them (De Angeli 2009, 7; Danaher 2017, 27 28). However, as (De Angeli 2009) argues, this is a "disputed critique often addressed towards violent video-games (Freier 2008; Whitby 2008)". Moreover, we may assume that, if extreme pornography can encourage sexual offences, then a fortiori simulated rape, where for example a sexbot does not indicate consent or explicitly indicates non-consent, would also pose the same problem. Nevertheless, a meta-meta-study (Ferguson and Hartley 2009) concludes that we must "discard the hypothesis that pornography contributes to increased sexual assault behaviour". Such uncertainty means that, as (Danaher 2017, 27-28) argues, sexbots (and presumably also social bots) may increase, decrease, or indeed have no effect on physical sexual offences that directly harm people. Hypothetical and indirect harms have thus not led to the criminalisation of sexbots ("Paedophiles Are Being Caught after They Order Child like Sex Dolls" 2017). Indeed, there is an argument to be made that sexbots can serve a therepeutic purpose (Devlin 2015). Hence, sexual offences as an area of AIC remains an open question.

\subsection{Theft and Fraud, and Forgery and Personation}

The literature we reviewed connects forgery and personation via AIC to theft and non-corporate fraud, and also implicates the use of machine learning in corporate fraud.

Concerning theft and non-corporate fraud, the literature describes a two-phase process that begins with using AI to gather personal data and proceeds to using stolen personal data and other AI methods to forge an identity that convinces the banking authorities to make a transaction (that is, involving banking theft and fraud). In the first phase of the AIC pipeline for theft and fraud, there are three ways for AI techniques to assist in gathering personal data.

The first method involves using social media bots to target users at large scale and low cost, by taking advantage of their capacity to generate posts, mimic people, and subsequently gain trust through friendship requests or "follows" on sites like Twitter, LinkedIn, and Facebook (Bilge et al. 2009). When a user accepts a friendship request, a potential criminal gains personal information, such as the user's location, telephone number, or relationship history, which are normally only available to that user's accepted friends (Bilge et al. 2009). Because many users add so-called friends whom they do not know, including bots, such privacy-compromising attacks have 
an unsurprisingly high success rate. Past experiments with a social bot exploited $30-40 \%$ of users in general (Bilge et al. 2009) and 60\% of users who shared a mutual friend with the bot (Boshmaf et al. 2012a). Moreover, identity-cloning bots have succeeded, on average, in having $56 \%$ of their friendship requests accepted on LinkedIn (Bilge et al. 2009). Such identity cloning may raise suspicion due to a user appearing to have multiple accounts on the same site (one real and one forged by a third-party). Hence, cloning an identity from one social network to another circumvents these suspicions, and in the face of inadequate monitoring such cross-site identity cloning is an effective tactic (Bilge et al. 2009), as discussed above.

The second method to gather personal data, which is compatible with and may even build on the trust gained via friending social media users, makes partial use of conversational social bots for social engineering (Alazab and Broadhurst 2016, 12). This occurs when AI

"attempts to manipulate behaviour by building rapport with a victim, then exploiting that emerging relationship to obtain information from or access to their computer (Chantler and Broadhurst 2006)".

Although the literature seems to support the efficacy of such bot-based social-engineering, given the currently limited capabilities of conversational AI, scepticism is justified when it comes to automated manipulation on an individual and long-term basis. However, as a short-term solution, a criminal may cast a deceptive social botnet sufficiently widely to discover susceptible individuals. Initial AI-based manipulation may gather harvested personal data and re-use it to produce "more intense cases of simulated familiarity, empathy, and intimacy, leading to greater data revelations" (Graeff 2014). After gaining initial trust, familiarity and personal data from a user, the (human) criminal may move the conversation to another context, such as private messaging, where the user assumes that privacy norms are upheld (Graeff 2014). Crucially, from here, overcoming the conversational deficiencies of AI to engage with the user is feasible using a cyborg; that is, a botassisted human (or vice versa) (Chu et al. 2010). Hence, a criminal may make judicious use of the otherwise limited conversational capabilities of $\mathrm{AI}$ as a plausible means to gather personal data.

The third method for gathering personal data from users is automated phishing. Ordinarily, phishing is unsuccessful if the criminal does not sufficiently personalise the messages towards the targetted user. Target-specific and personalised phishing attacks (known as spear phishing), which have been shown to be four times more successful than a generic approach (Jagatic et al. 2007), is labour intensive. However, cost-effective spear phishing is possible using automation (Bilge et al. 2009), which researchers have demonstrated to be feasible by using machine-learning techniques to craft messages personalised to a specific user (Seymour and Tully 2016a). 
In the second phase of AI-supported banking fraud, AI may support the forging of an identity, including via recent advances in voice synthesis technologies (Bendel 2017). Using the classification and generation capabilities of machine learning, Adobe's software is able to learn adversarially and reproduce someone's personal and individual speech pattern from a twentyminute recording of the replicatee's voice [p.1]. Bendel argues that AI-supported voice synthesis raises a unique threat in theft and fraud, which

\footnotetext{
“could use VoCo and Co [Adobe's voice editing and generation software] for biometric security processes and unlock doors, safes, vehicles, and so on, and enter or use them. With the voice of the customer, they [criminals] could talk to the customer's bank or other institutions to gather sensitive data or to make critical or damaging transactions. All kinds of speech-based security systems could be hacked.” [p.3]
}

Credit card fraud is predominantly an online offence (Office for National Statistics 2016), which occurs when "the credit card is used remotely; only the credit card details are needed" (Delamaire, Abdou, and Pointon 2009). Because credit card fraud typically neither requires physical interaction nor embodiment, AI may drive fraud by providing voice synthesis or helping to gather sufficient personal details.

In the case of corporate fraud, AI used for detection may also make fraud easier to commit. Specifically,
"when the executives who are involved in financial fraud are well aware of the fraud detection techniques and software, which are usually public information and are easy to obtain, they are likely to adapt the methods in which they commit fraud and make it difficult to detect the same, especially by existing techniques" (Zhou and Kapoor 2011).

More than identifying a specific case of AIC, this use of AI highlights the risks of over-reliance on AI for detecting fraud, which may aid fraudsters. These thefts and frauds concern real-world money. A virtual world threat is whether social bots may commit crimes in massively multiplayer online game (MMOG) contexts. These online games often have complex economies, where the supply of in-game items is artificially restricted, and where intangible in-game goods can have realworld value if players are willing to pay for them; items in some cases costing in excess of US $\$ 1000$ (Y. Chen et al. 2004, 1). So it is not surprising that, from a random sample of 613 criminal prosecutions in 2002 of online game crimes in Taiwan, virtual property thieves exploited users' compromised credentials 147 times [p.1. Fig XV] and stolen identities 52 times(Y.-C. Chen et al. 
2005). Such crimes are analogous to the use of social bots to manage theft and fraud at large scale on social media sites, and the question is whether AI may become implicated in this virtual crime space.

Having outlined and discussed the potential for AIC as currently described in the academic literature, the time has come to analyse the solutions that are currently available. This is the task of the next section.

\section{Possible Solutions for Artificial Intelligence-Supported Crime}

\subsection{Tackling Emergence}

There are a number of legal and technological solutions that can be considered in order to address the issue of emergent behaviour. Legal solutions may involve limiting agents' autonomy or their deployment. For example, Germany has created deregulated contexts where testing of self-driving cars is permitted, if the vehicles remain below an unacceptable level of autonomy, in order to

"to collect empirical data and sufficient knowledge to make rational decisions for a number of critical issues" (Pagallo 2017a, 7).

Hence, the solution is that, if legislation does not prohibit higher levels of autonomy for a given AA, the law obliges that this liberty is coupled with technological remedies to prevent emergent criminal acts or omissions once deployed in the wild.

One possibility is to require developers to deploy AAs only when they have run-time legal compliance layers, which take declarative specifications of legal rules and impose constraints on the run-time behaviour of AAs. Whilst still the the focus of ongoing research, approaches to runtime legal compliance includes architectures for trimming non-compliant AA plans (Meneguzzi and Luck 2009; Vanderelst and Winfield 2016a); and provably correct temporal logic-based formal frameworks that select, trim or generate AA plans for norm compliance (Riemsdijk et al. 2013; Riemsdijk, Dennis, and Fisher 2015; Dennis et al. 2016). In a multi-agent setting, AIC can emerge from collective behaviour, hence MAS-level compliance layers may modify an individual AA's plans, in order to prevent wrongful collective actions (Uszok et al. 2003; Bradshaw et al. 1997; Tonti, Bradshaw, and Jeffers 2003). Essentially, such technical solutions propose regimenting compliance (making non-compliance impossible, at least to the extent that any formal proof is applicable to real-world settings) with predefined legal rules within a single AA or a MAS (Andrighetto et al. 2013, 4:105).

However, the shift of these approaches from mere regulation, which leaves deviation from the norm physically possible, to regimentation, may not be desirable when considering the impact 
on democracy and the legal system. These approaches implement Lessig's code-as-law concept (Lessig 1999), which considers

"software code as a regulator in and of itself by saying that the architecture it produces can serve as an instrument of social control on those that use it" (Graeff 2014, 4).

As (Hildebrandt 2008) objects:

"while computer code generates a kind of normativity similar to law, it lacks_-precisely because it is NOT law- $[\ldots]$ the possibility of contesting its application in a court of law. This is a major deficit in the relationship between law, technology and democracy".

If code-as-law entails a democratic and legal contestation deficit, then a fortiori addressing emergent AIC with a legal reasoning layer comprising normative but uncontestable code, as compared to the contestable law from which it derives, bears the same problems.

Social simulation can address an orthogonal problem, whereby an AA owner may choose to operate outside of the law and any such legal reasoning layer requirements (Vanderelst and Winfield 2016b, 4). The basic idea is to use simulation as a test bed before deploying AAs in the wild. For example, in a market context, regulators would

"act as "certification authorities", running new trading algorithms in the system-simulator to assess their likely impact on overall systemic behavior before allowing the owner/developer of the algorithm to run it "live"” (Cliff and Northrop 2012, 19).

Private corporations could fund such extensive social simulations, as a common good, and as a replacement for (or in addition to) proprietary safety measures (Cliff and Northrop 2012, 21). However, a social simulation is a model of an inherently chaotic system, making it a poor tool for specific predictions (Edmonds and Gershenson 2013, 12). Nonetheless, the idea may still be successful, as it focuses on detecting the strictly qualitative possibility of previously unforeseen and emergent events in a MAS (Edmonds and Gershenson 2013, 13).

\subsection{Addressing Liability}

Although liability is an extensive topic, we outline here four models that we extracted from the literature review (Hallevy 2008, 13): direct liability; perpetration-by-another; command responsibility; and natural probable consequence.

The direct liability model ascribes the factual and mental elements to an AA, representing a dramatic shift from the anthropocentric view of AAs as tools, to AAs as (potentially equal) decision 
makers (Lier 2016). Some argue for holding an AA directly liable because "the process of analysis in AI systems parallels that of human understanding" (Hallevy 2008, 15), by which we understand the author to mean that, as (Dennett 1987) argues, we may treat any agent, for practical purposes, as if it possesses mental states. However, a fundamental limitation of this model is that AAs do not currently have (separate) legal personality and agency, and thus we cannot hold an AA legally liable in its own capacity (regardless of whether or not this is desirable in practice.) Similarly, it has been noted that AAs cannot contest a guilty verdict, and that

"if a subject cannot take the stand in a court of law it cannot contest the incrimination, which would turn the punishment into discipline" (Hildebrandt 2008).

Moreover, legally, at the moment AAs cannot meet the mental element; meaning that the

"common legal standpoint excludes robots from any kind of criminal responsibility because they lack psychological components such as intentions or consciousness" (Pagallo 2011).

This lack of actual mental states becomes clear when considering that an AA's understanding of a symbol (that is, a concept) is limited to its grounding on further syntactic symbols (Taddeo and Floridi 2005), thus leaving the mens rea in limbo. Lack of a guilty mind does not prevent the mental state from being imputed to the AA (just as a corporation may have the mental state of its employees imputed to it and hence, as an organisation, may be found liable) but, for the time being, liability of an AA would still require it to have legal personality. A further problem is that holding an AA solely liable may prove unacceptable, since it would lead to a de-responsibilisation of the human agents behind an AA (e.g., the engineer, user, or corporation), which is likely to weaken the dissuasive power of criminal law.

To ensure the criminal law is effective, as (Floridi 2016, 8) proposes, we may shift the burden of liabilities onto the humans-and corporate or other legal agents-who made a (criminally bad) difference to the system, such as the various engineers, users, vendors, and so forth, whereby "if the design is poor and the outcome faulty, then all the [human] agents involved are deemed responsible". The next two models discussed in the literature move in this direction, focusing on the liability of human or other legal persons involved in producing and using the AA.

The perpetration-by-another model (Hallevy 2008, 4), which uses intention as the standard of mens rea, frames the AA as an instrument of crime where "the party orchestrating the offence (the perpetrator-by-another) is the real perpetrator". Perpetration-by-another leaves 
"three human candidates for responsibility before a criminal court: programmers, manufacturers, and users of robots [AAs]" (Pagallo 2017b).

Clarifying intent is crucial to applying perpetration-by-another. Concerning social media, "developers who knowingly create social bots to engage in unethical actions are clearly culpable" (de Lima Salge and Berente 2017). For further clarity, as (Arkin 2008, 76) argues, designers and programmers should be required to ensure that AAs refuse a criminal order (and that only the deployer can explicitly override), which would remove ambiguity from intent and therefore liability (Arkin and Ulam 2012). This means that, to be liable, an AA's deployer must intend the harm by overriding the AA's default position of 'can but will not do harm'. Hence, together with technological controls, and viewing an AA as a mere instrument of AIC, perpetration-by-another addresses those cases where a deployer intends to use an AA to commit an AIC.

The command responsibility model, which uses knowledge as the standard of mens rea, ascribes liability to any military officer who knew about (or should have known) and failed to take reasonable steps to prevent crimes committed by their forces, which could in the future include AAs (McAllister 2017, 38). Hence, command responsibility is compatible, or may even be seen as an instance of, perpetration-by-another, for use in contexts where there is a chain of command, such as within the military and police forces. This model is normally clear on how

"liability should be distributed among the commanders to the officers in charge of interrogation to the designers of the system" (McAllister 2017, 39).

However,

"issues on the undulating waves of increasing complexity in programming, robo-human relationships, and integration into hierarchical structures, call into question these theories' sustainability" (McAllister 2017, 39).

The natural-probable-consequence liability model, which uses negligence or recklessness as the standard of mens rea, addresses AIC cases where an AA developer and user neither intend nor have a priori knowledge of an offence (Hallevy 2008, 7). Liability is ascribed to the developer or user if the harm is a natural and probable consequence of their conduct, and they recklessly or negligently exposed others to the risk (Hallevy 2008, 8-9), such as in cases of AI-caused emergent market manipulation (Wellman and Rajan 2017, 4).

Natural-probable-consequence and command responsibility are not new concepts; they are both analogous with the respondent superior principle entailed by 
"rules as old as Roman law, according to which the owner of an enslaved person was responsible for any damage caused by that person" (Floridi 2017b, 4).

However, it might not always be obvious

"which programmer was responsible for a particular line of code, or indeed the extent to which the resulting programme was the result of the initial code or the subsequent development of that code by the ML [Machine Learning] system” (Williams 2017).

Such ambiguity means that when emergent AIC is a possibility, some suggest that AAs should be banned "to address matters of control, security, and accountability" (Joh 2016, 18) —which at least would make liability for violating such a ban clear. However, others argue that a possible ban in view of the risk of emerging AIC should be balanced carefully against the risk of hindering innovation; it will therefore be crucial to provide a suitable definition of the standard of negligence (Gless, Silverman, and Weigend 2016,17) to ensure that an all-out ban is not considered to be the only solution-given it would end up dissuading the design of AAs that compare favourably to people in terms of safety.

\subsection{Monitoring}

We have identified four possible mechanisms for addressing AIC monitoring in the relevant literature.

The first suggestion is to devise AIC predictors using domain knowledge. This would overcome the limitation of more generic machine learning classification methods; that is, where the features used for detection can also be used for evasion. Predictors specific to financial fraud can consider institutional properties (Zhou and Kapoor 2011), such as objectives (e.g., whether the benefits outweigh the costs), structure (e.g., a lack of an auditing committee), and the management's (lack of) moral values (the authors do not say which, if any, of these values are actually predictive). Predictors for identity theft (for example, profile cloning), have involved prompting users to consider whether the location of the "friend" that is messaging them meets their expectation (Bilge et al. 2009).

The second suggestion discussed in the literature is to use social simulation to discover crime patterns (Wellman and Rajan 2017, 14). However, pattern discovery must contend with the sometimes limited capacity to bind offline identities to online activities. For example, in markets, it takes significant effort to correlate multiple orders with a single legal entity, and consequently "manipulative algos [algorithms] may be impossible to detect in practice" (Farmer and Skouras 2013, 17). Furthermore, on social media 
"an adversary controls multiple online identities and joins a targeted system under these identities in order to subvert a particular service" (Boshmaf et al. 2012b).

The third suggestion is to address traceability by leaving tell-tale clues in the components that make up AIC instruments. For example, physical traces left by manufacturers in AA hardware, such as UUVs used to traffic drugs, or fingerprinting in third-party AI software (Sharkey, Goodman, and Ross 2010). Adobe's voice replication software takes this approach. It places a watermark in the generated audio (Bendel 2017, 2). However, lack of knowledge and control over who develops AI instrument components (used for AIC) limits traceability via watermarking and similar techniques.

The fourth suggestion is aimed at cross-system monitoring, and utilises self-organisation across systems (Lier 2016). The idea, originating in (Luhmann 1995), begins with the conceptualisation of one system (e.g., a social media site) taking on the role of a moral ${ }^{8}$ agent, and a second system (e.g., a market) taking the role of the moral patient. A moral patient is any receiver of moral actions (Floridi 2013, 135). The conceptualisation chosen by (Lier 2016) determines that the following are all systems: at the lowest atomic level an artificial or human agent; at a higher level any MAS such as a social media platform, markets, and so on; and, generalising further, any system-of-systems. Hence, any such human, artificial, or mixed system can qualify as a moral patient or a moral agent. Whether an agent is indeed a moral agent (Floridi 2013, 147) hinges on whether the agent can undertake actions that are morally qualifiable, but not on whether the moral agent can or should be held morally responsible for those actions [p.150-152].

Adopting this moral-agent and moral-patient distinction, Lier proposes a process to monitor and address crimes and effects that traverse systems, involving four steps (Lier 2016), which we give generically and exemplify specifically: information-selection of the moral agent's internal actions for relevance to the moral-patient (e.g., posts users make on social media); utterance of the selected information from the moral-agent to the moral-patient (e.g., notifying a financial market of social media posts); assessment by the moral-patient of the normativity of the uttered actions (e.g., whether social media posts are part of a pump-and-dump scheme); and feedback given by the moralpatient to the moral-agent (e.g., notifying a social media site that a user is conducting a pump-anddump scheme, upon which the social media site should act). This final step completes a "feedback loop [that] can create a cycle of machine learning in which moral elements are simultaneously

\footnotetext{
8 The adjective "moral" is taken from the cited work, which considers unethical behaviour to constitute crossing system boundaries, whereas here we are concerned with criminal acts or omissions, which may have a negative, neutral, or positive ethical evaluation. We use "moral" to avoid misrepresenting the cited work, and not to imply that the criminal law coincides with ethics.
} 
included" (Lier 2016, 11), such as a social media site learning and adjusting to the normativity of its behaviour from a market's perspective.

A similar self-organisation process could be used to address other AIC areas. Creating a profile on Twitter (the moral agent) could have relevance to Facebook (the moral patient) concerning identity theft (information-selection). By notifying Facebook of the newly created profile details (utterance), Facebook could determine whether it constitutes identity theft by asking the relevant user (understanding), and notifying Twitter to take appropriate action (feedback).

\subsection{Psychology}

The literature raises two concerns over the psychological element of AIC: manipulation of users and, (in the case of anthropomorphic AI) creation in a user of a desire to commit a crime. Our literature analysis only provided suggested solutions for this second, contentious problem of anthropomorphism.

If anthropomorphic AAs are a problem, then the literature offers two remedies. One is to ban or restrict anthropomorphic AAs that make it possible to simulate crime. This position leads to a call for restricting anthropomorphic AAs in general, because they "are precisely the sort of robots [AAs] that are most likely to be abused" (Whitby 2008, 6). Cases whereby social bots are "designed, intentionally or not, with a gender in mind, [...] attractiveness and realism of female agents" raise the question "if ECA's [that is, social bots] encourage gender stereotypes will this impact on real women on-line?” (De Angeli 2009, 11). The suggestion is to make it unacceptable for social bots to emulate anthropomorphic properties, such as having a perceived gender or ethnicity. Concerning sexbots that emulate sexual offences, a further suggestion is to enact a ban as a "package of laws that help to improve social sexual morality" and make norms of intolerance clear (Danaher 2017, 29-30).

A second suggestion (albeit incompatible with the first one) is to use anthropomorphic AAs as a way to push back against simulated sexual offences. For example, concerning the abuse of artificial pedagogical agents, "we recommend that agent responses should be programmed to prevent or curtail further student abuse" (Veletsianos, Scharber, and Doering 2008, 8). As (Darling 2016, 14) argues

"not only would this combat desensitisation and negative externalities from people's behavior, it would preserve the therapeutic and educational advantages of using certain robots more like companions than tools." 
Implementing these suggestions requires choosing whether to criminalise the demand or supplyside of the transaction, or both. Users may be in the scope of applying punishments. At the same time one may argue that

"as with other crimes involving personal "vice", suppliers and distributors could also be targeted on the grounds that they facilitate and encourage the wrongful acts. Indeed, we might exclusively or preferentially target them, as is now done for illicit drugs in many countries" (Danaher 2017, 33).

\section{Conclusions}

In this article, we provided the first systematic literature analysis of AI-Crime (AIC), in order to answer two questions. We answered the first question-What are the fundamentally unique and feasible threats posed by AIC? — on the basis of the classic counterfactual definition of AI and, therefore, we have focused on $\mathrm{AI}$ as a reservoir of autonomous smart agency. The threats were described area by area (in terms of specific defined crimes) and more generally (in terms of the AI qualities and issues of emergence, liability, monitoring, and psychology). We addressed the second question — which solutions are available or may be devised to deal with AIC? - by focusing on both general and cross-cutting themes, and by providing an up-to-date picture of the societal, technological, and legal solutions available, and their limitations. Because we have extracted the literature's suggested remedies for this set of (inevitably) cross-cutting themes, the solutions, even if only partial, will apply to multiple AIC areas. The huge uncertainty over what we already know about AIC (in terms of area-specific threats, general threats, and solutions) is now reduced. More broadly, AIC research is still in its infancy and hence, based on our analysis, we now provide a tentative vision for five dimensions of future AIC research.

Areas. Understanding the areas of AIC better requires extending current knowledge, particularly concerning: the use of AI in interrogation, which was only addressed by one liabilityfocused paper; and theft and fraud in virtual spaces (e.g., online games with intangible assets that hold real-world value; and AAs committing emergent market manipulation, which research has seemingly only been studied in experimental simulations). Our analysis revealed social engineering attacks as a plausible concern, but lacking in real-world evidence for the time being. Homicide and terrorism appear to be notably absent from the AIC literature, though they demand attention in view of AI-fuelled technologies such as pattern recognition (e.g., when members of vulnerable groups are unfairly targeted as victims by perpetrators or suspects by law-enforcement officials), weaponised drones, and self-driving vehicles; all of which may have lawful and criminal uses. 
Dual-use. The digital nature of AI facilitates its dual-use (Moor 1985, 4; Floridi 2010, 260), making it feasible that applications designed for legitimate uses may then be implemented to commit criminal offences. This is the case for UUVs, for example. The further AI is developed and the more its implementations become pervasive, the higher the risk of malicious or criminal uses. Left unaddressed, such risks may lead to societal rejection and excessively strict regulation of these AI-based technologies. In turn, the technological benefits to individuals and societies may be eroded as AI's use and development is increasingly constrained (Floridi and Taddeo 2016, 2). Such limits have already been placed on machine learning research into visual discriminators of homosexual and heterosexual men (Y. Wang and Kosinski 2017), which was considered too dangerous to release in full (i.e., with the source code and learned data structures) to the wider research community, at the expense of scientific reproducibility. Even when such costly limitations on AI releases are not necessary, as Adobe demonstrated by embedding watermarks into voice reproducing technology (Bendel 2017), external and malevolent developers may nevertheless reproduce the technology in the future. Anticipating AI's dual-use beyond the general techniques revealed in our analysis, and the efficacy of policies for restricting release of AI technologies, requires further research. This is particularly the case of the implementation of AI for cybersecurity.

Security. The AIC literature reveals that, within the cybersecurity sphere, AI is taking on a malevolent and offensive role-in tandem with defensive AI systems being developed and deployed to enhance their resilience (in enduring attacks) and robustness (in averting attacks), and to counter threats as they emerge (Yang et al. 2018). The 2016 DARPA Cyber Grand Challenge was a tipping point for demonstrating the effectiveness of a combined offensive-defensive AI approach, with seven AI systems shown to be capable of identifying and patching their own vulnerabilities, while also probing and exploiting those of competing systems. More recently, IBM launched Cognitive SOC (“Cognitive Security - Watson for Cyber Security | IBM” 2018). This is an application of a machine-learning algorithm that uses an organisation's structured and unstructured security data, "including imprecise human language contained in blogs, articles, reports," to elaborate information about security topics and threats, with the goal of improving threat identification, mitigation, and responses. Of course, while policies will obviously play a key role in mitigating and remedying the risks of dual-uses after deployment (for example, by defining oversight mechanisms), it is at the design stage that these risks are addressed properly. Yet, contrary to a recent report on malicious AI (Brundage et al. 2018), which suggests that "one of our best hopes to defend against automated hacking is also via AI" [p.65], our AIC analysis suggests that over-reliance on AI can be counter-productive. All of which emphasises the need for further 
research into AI in cybersecurity-but also into alternatives to AI, such as focussing on people and social factors.

Persons. Although the literature raised the possibility of psychological factors (e.g., trust) in AI's crime role, research is lacking on the personal factors that may create perpetrators, such as programmers and users of AI for AIC, in the future. Now is the time to invest in longitudinal studies and multivariate analysis spanning educational, geographical, and cultural backgrounds of victims, and perpetrators or even benevolent AI developers, that will help to predict how individuals come together to commit AIC. For example, to understand the efficacy of ethics courses in Computer Science programmes, and the capacity to educate users to be less trustful of potentially AI-driven agents in cyberspace.

Organisation. Europol's most recent four-yearly report (Europol 2017) on the serious and organised crime threat, highlights the ways in which the type of technological crime tends to correlate with particular criminal-organisation topologies. The AIC literature indicates that AI may play a role in criminal organisations such as drug cartels, which are well-resourced and highly organised. Conversely, ad hoc criminal organisation on the dark web already takes place under what Europol refers to as crime-as-a-service. Such criminal services are sold directly between buyer and seller, potentially as a smaller element in an overall crime, which AI may fuel (e.g., by enabling profile hacking) in the future. ${ }^{9}$ On the spectrum ranging from tightly-knit to fluid AIC organisations there exist many possibilities for criminal interaction; identifying the organisations that are essential or that seem to correlate with different types of AIC will further our understanding of how AIC is structured and operates in practice. Indeed, AI poses a significant risk, because it may deskill crime, and hence cause the expansion of what Europol calls the criminal sharing economy.

Developing our understanding of these dimensions is essential if we are to track and disrupt successfully the inevitable future growth of AIC. Hence, our analysis of the literature is intended to spark further research into the very serious, growing, but still relatively unexplored concerns over AIC. The sooner we understand this new crime phenomenon, the earlier we shall be able to put into place preventive, mitigating, disincentivesing, and redressing policies.

\footnotetext{
9 To this end a cursory search for "Artificial Intelligence" on prominent darkweb markets returned a negative result. Specifically, we checked: "Dream Market", "Silk Road 3.1", and "Wallstreet Market". The negative result is not indicative of AIC-as-a-service's absence on the darkweb, which may exist under a different guise or on more specialised markets. For example some services offer to extract personal information from a user's computer, and even if such services are genuine the underlying technology (e.g., AI-fuelled pattern recognition) remains unknown.
} 


\section{References}

Alaieri, Fahad, and André Vellino. 2016. "Ethical Decision Making in Robots: Autonomy, Trust and Responsibility." Lecture Notes in Computer Science (Including Subseries Lecture Notes in Artificial Intelligence and Lecture Notes in Bioinformatics) 9979 LNAI: 159-68. https://doi.org/10.1007/978-3-319-47437-3_16.

Alan M. Turing. 1950. "Computing Machinery and Intelligence." Mind 59 (236): 433-60.

Alazab, Mamoun, and Roderic Broadhurst. 2016. "Spam and Criminal Activity." Trends and Issues in Crime and Criminal Justice 526. https:/ / doi.org/10.1080/016396290968326.

Alvisi, Lorenzo, Allen Clement, Alessandro Epasto, Silvio Lattanzi, and Alessandro Panconesi. 2013. "SoK: The Evolution of Sybil Defense via Social Networks." Proceedings - IEEE Symposium on Security and Privacy, no. 2: 382-96. https://doi.org/10.1109/SP.2013.33.

Anderson, Kenneth, and Matthew C. Waxman. 2013. "Law and Ethics for Autonomous Weapon Systems: Why a Ban Won't Work and How the Laws of War Can." Social Science Research Network (SSRN) Electronic Journal 11: 1-32. https://doi.org/10.2139/ssrn.2250126.

Andrighetto, Giulia, Guido Governatori, Pablo Noriega, and Leendert van der Torre. 2013. Normative Multi-Agent Systems. Dagstubl Follow-Ups. Vol. 4. Schloss Dagstuhl-LeibnizZentrum fuer Informatik.

Angeli, Antonella De. 2009. "Ethical Implications of Verbal Disinhibition with Conversational Agents." Psychology Journal 7 (1): 49-57.

Angeli, Antonella De, and Sheryl Brahnam. 2008. "I Hate You! Disinhibition with Virtual Partners." Interacting with Computers $20 \quad$ (3): $\quad 302-10$. https://doi.org/10.1016/j.intcom.2008.02.004.

Archbold, JF. 2018. Criminal Pleading, Evidence and Practice. London: Sweet \& Maxwell Ltd.

Arkin, Ronald C. 2008. "Governing Lethal Behavior: Embedding Ethics in a Hybrid Deliberative/Reactive Robot Architecture Part I: Motivation And Philosophy." In Proceedings of the 3rd International Conference on Human Robot Interaction - HRI '08. https://doi.org/10.1145/1349822.1349839.

Arkin, Ronald C, and Patrick Ulam. 2012. "Overriding Ethical Constraints in Lethal Autonomous Systems." Technical Report GIT-MRL-12-01, 1-8.

Ashworth, Andrew. 2010. "Should Strict Criminal Liability Be Removed from All Imprisonable Offences?" Irish Jurist 45.

Bendel, Oliver. 2017. "The Synthetization of Human Voices." AI \& SOCIETY Online First.

Bilge, Leyla, Thorsten Strufe, Davide Balzarotti, Engin Kirda, and Sophia Antipolis. 2009. "All Your Contacts Are Belong to Us : Automated Identity Theft Attacks on Social Networks." Www 2009, 551-60. http://doi.acm.org/10.1145/1526709.1526784.

Boshmaf, Yazan, Ildar Muslukhov, Konstantin Beznosov, and Matei Ripeanu. 2012a. "Design and Analysis of a Social Botnet." Computer Networks 57: 556-78. https://doi.org/10.1016/j.comnet.2012.06.006.

. 2012b. "Key Challenges in Defending Against Malicious Socialbots." USENIX Workshop on Large-Scale Exploits and Emergent Threats, 1-4. https://doi.org/10.1016/j.comnet.2012.06.006.

Bradshaw, Jm Jeffrey M, Stewart Dutfield, Pete Benoit, and John D Jd Woolley. 1997. "KAoS: Toward an Industrial-Strength Open Agent Architecture." Software Agents, 375-418.

Brundage, Miles, Shahar Avin, Jack Clark, Helen Toner, Peter Eckersley, Ben Garfinkel, Allan Dafoe, et al. 2018. "The Malicious Use of Artificial Intelligence: Forecasting, Prevention, and Mitigation."

Cath, Corinne, Sandra Wachter, Brent Mittelstadt, Mariarosaria Taddeo, and Luciano Floridi. 2017. "Artificial Intelligence and the 'Good Society': The US, EU, and UK Approach." Science and Engineering Ethics, no. 604: 1-23.

Chantler, Alan, and Roderic Broadhurst. 2006. "Social Engineering and Crime Prevention in Cyberspace." Queensland University of Technology, 22. 
Chen, Y, P Chen, R Song, and L Korba. 2004. "Online Gaming Crime and Security Issues - Cases and Countermeasures from Taiwan." Proceedings of the 2 nd Annual Conference on Privacy, Security and Trust.

Chen, Ying-Chieh, Patrick S. Chen, Jing-Jang Hwang, Larry Korba, Song Ronggong, and George Yee. 2005. "An Analysis of Online Gaming Crime Characteristics.” Internet Research 15 (3): 246-61.

Chu, Zi, Steven Gianvecchio, Haining Wang, and Sushil Jajodia. 2010. "Who Is Tweeting on Twitter: Human, Bot, or Cyborg?" Acsac 2010, 21. https://doi.org/10.1145/1920261.1920265.

Cliff, Dave, and Linda Northrop. 2012. "The Global Financial Markets: An Ultra-Large-Scale Systems Perspective." In Monterey Workshop 2012: Large-Scale Complex IT Systems. Development, Operation and Management, 29-70. https://doi.org/10.1007/978-3-642-340598_2.

"Cognitive Security - Watson for Cyber Security | IBM." 2018. 2018. https://www.ibm.com/security/cognitive.

Danaher, John. 2017. "Robotic Rape and Robotic Child Sexual Abuse: Should They Be Criminalised?" Criminal Law and Philosopby 11 (1): 71-95. https://doi.org/10.1007/s11572014-9362-x.

Darling, Kate. 2016. “'Who's Johnny' Anthropomorphic Framing in Human-Robot Interaction, Integration, and Policy." In Robot Ethics 2.

"Deep Fakes: A Looming Crisis for National Security, Democracy and Privacy?" 2018. Lawfare. February 21, 2018. https://www.lawfareblog.com/deep-fakes-looming-crisis-nationalsecurity-democracy-and-privacy.

Delamaire, Linda, Hussein Abdou, and John Pointon. 2009. "Credit Card Fraud and Detection Techniques: A Review." Banks and Bank Systems 4 (2).

Dennett, D.C. 1987. The Intentional Stance. Cambridge, MA: MIT Press.

Dennis, Louise, Michael Fisher, Marija Slavkovik, and Matt Webster. 2016. "Formal Verification of Ethical Choices in Autonomous Systems." Robotics and Autonomous Systems 77: 1-14. https://doi.org/10.1016/j.robot.2015.11.012.

Devlin, Kate. 2015. "In Defence of Sex Machines: Why Trying to Ban Sex Robots Is Wrong." The Conversation.

Edmonds, B, and Carlos Gershenson. 2013. "Modelling Complexity for Policy: Opportunities and Challenges." Handbook on Complexity and Public Policy.

Europol. 2017. "Serious and Organised Crime Threat Assessment." European Union. https://www.europol.europa.eu/socta/2017/.

Ezrachi, Ariel, and Maurice E. Stuck. 2016. "Two Artificial Neural Networks Meet in an Online Hub and Change the Future (of Competition, Market Dynamics and Society)." Oxford Legal Studies Research Paper No. 24/2017 University of Tennessee Legal Studies Research Paper No. 323.

Farmer, J. Doyne, and Spyros Skouras. 2013. "An Ecological Perspective on the Future of Computer Trading." Quantitative Finance 13 (3): 325-46. https://doi.org/10.1080/14697688.2012.757636.

Ferguson, Christopher J., and Richard D. Hartley. 2009. "The Pleasure Is Momentary...the Expense Damnable?. The Influence of Pornography on Rape and Sexual Assault." Aggression and Violent Behavior 14 (5): 323-29. https://doi.org/10.1016/j.avb.2009.04.008.

Ferrara, Emilio. 2015. "Manipulation and Abuse on Social Media." https://doi.org/10.1145/2749279.2749283.

Ferrara, Emilio, Onur Varol, Clayton Davis, Filippo Menczer, and Alessandro Flammini. 2014. "The Rise of Social Bots." Communications of the ACM 59 (7): 96-104. https://doi.org/10.1145/2818717.

Floridi, Luciano. 2010. The Cambridge Handbook of Information and Computer Ethics. . 2013. The Ethics of Information. Oxford University Press. 
2016. "Faultless Responsibility: On the Nature and Allocation of Moral Responsibility for Distributed Moral Actions." Royal Society's Philosophical Transactions A, 1-22. https://doi.org/10.1098/rsta.2016.0112.

. 2017a. "Digital's Cleaving Power and Its Consequences." Philosophy \& Technology 30 (2): 123-29.

2017b. "Robots, Jobs, Taxes, and Responsibilities." Philosophy \& Technology 30 (1): 1-4.

Floridi, Luciano, and J. W. Sanders. 2004. "On the Morality of Artificial Agents." Minds and Machines 14 (3): 349-79. https://doi.org/10.1023/B:MIND.0000035461.63578.9d.

Floridi, Luciano, and Mariarosaria Taddeo. 2016. "What Is Data Ethics?” Philosophical Transactions of the Royal Society A: Mathematical, Physical and Engineering Sciences 374 (2083). https://doi.org/10.1098/rsta.2016.0360.

Freier, N. 2008. "Children Attribute Moral Standing to a Personified Agent." Proceeding of the TwentySixth Annual CHI Conference on Human Factors in Computing Systems (CHI '08), 343-52. https://doi.org/10.1145/1357054.1357113.

Freitas, Pedro Miguel, Francisco Andrade, and Paulo Novais. 2014. "Criminal Liability of Autonomous Agents: From the Unthinkable to the Plausible." In Ai Approaches to the Complexity of Legal Systems, 145-56.

Gauci, Melvin, Jianing Chen, Wei Li, Tony J Dodd, and Roderich Gross. 2014. "Clustering Objects with Robots That Do Not Compute." In Proceedings of the 2014 International Conference on Autonomous Agents and Multi-Agent Systems (AAMAS 2014), 421-28. International Foundation for Autonomous Agents and Multiagent Systems.

Gless, Sabine, Emily Silverman, and Thomas Weigend. 2016. "If Robots Cause Harm, Who Is to Blame? Self-Driving Cars and Criminal Liability.” New Criminal Law Review 19 (3): 412-36. https://doi.org/10.1525/sp.2007.54.1.23.

Gogarty, Brendan, and Meredith Hagger. 2008. "The Laws of Man over Vehicles Unmanned : The Legal Response to Robotic Revolution on Sea , Land and Air." Journal of Law, Information and Science 19: 73-145. https://doi.org/10.1525/sp.2007.54.1.23.

Golder, S. A., and M. W. Macy. 2011. "Diurnal and Seasonal Mood Vary with Work, Sleep, and Daylength Across Diverse Cultures." Science 333 (6051): 1878-81. https://doi.org/10.1126/science.1202775.

Graeff, Erhardt C. 2014. "What We Should Do Before the Social Bots Take Over: Online Privacy Protection and the Political Economy of Our Near Future." MIT Media Arts and Sciences.

Grut, Chantal. 2013. "The Challenge of Autonomous Lethal Robotics to International Humanitarian Law." Journal of Conflict and Security Law 18 (1): 5-23. https://doi.org/10.1093/jcsl/krt002.

Hallevy, Gabriel. 2008. "Unmanned Vehicles - Subordination to Criminal Law under the Modern Concept of Criminal Liability" 124: 122-24.

Hay, George A, and Daniel Kelley. 1974. "An Empirical Survey of Price Fixing Conspiracies." The Journal of Law and Economics 17 (1).

Hildebrandt, Mireille. 2008. "Ambient Intelligence, Criminal Liability and Democracy." Criminal Law and Philosophy 2 (2): 163-80. https://doi.org/10.1007/s11572-007-9042-1.

Jagatic, Tom N., Nathaniel A. Johnson, Markus Jakobsson, and Filippo Menczer. 2007. "Social Phishing." Communications of the ACM 50 (10): 94-100. https://doi.org/10.1145/1290958.1290968.

James Gips. 1995. “Towards the Ethical Robot.” Android Epistemology, 243-52.

Janoff-Bulman, Ronnie. 2007. "Erroneous Assumptions: Popular Belief in the Effectiveness of Torture Interrogation." Peace and Conflict: Journal of Peace Psychology 13 (4): 429.

Joh, Elizabeth E. 2016. "Policing Police Robots." In Imagining the Legal Landscape: Technology and the Law in 2030 Policing, 516:516-43.

Kerr, Ian R. 2004. "Bots, Babes and the Californication of Commerce." University of Ottawa Law \& Technology Journal, 287-324. 
Kerr, Ian R, and Marcus Bornfreund. 2005. "Buddy Bots: How Turing's Fast Friends Are UnderMining Consumer Privacy." Presence: Teleoperators and Virtual Environments, 647-55.

Kolosnjaji, Bojan, Ambra Demontis, Battista Biggio, Davide Maiorca, Giorgio Giacinto, Claudia Eckert, and Fabio Roli. 2018. "Adversarial Malware Binaries: Evading Deep Learning for Malware Detection in Executables." ArXiv:1803.04173 [Cs], March. http://arxiv.org/abs/1803.04173.

Lessig, Lawrence. 1999. Code and Other Laws of Cyberspace. New York: Basic Books.

Lier, Ben Van. 2016. "From High Frequency Trading to Self-Organizing Moral Machines" 7 (1): 34-50. https://doi.org/10.4018/IJT.2016010103.

Lima Salge, Carolina Alves de, and Nicholas Berente. 2017. "Is That Social Bot Behaving Unethically?" Communications of the ACM 60 (9): 29-31. https://doi.org/10.1145/3126492.

Lin, Tom C W, Jim Fanto, Jill Fisch, Joan Heminway, Duncan Hollis, Kristin Johnson, Wulf Kaal, et al. 2017. "The New Market Manipulation.” Emory Law Journal 66: 1253.

Luciano Floridi, Mariarosaria Taddeo, and Matteo Turilli. 2009. “Turing's Imitation Game: Still an Impossible Challenge for All Machines and Some Judges—an Evaluation of the 2008 Loebner Contest." Minds and Machines 19 (1): 145-50.

Luhmann, Niklas. 1995. Social Systems. Stanford: Stanford University Press.

Mackey, Tim K., Janani Kalyanam, Takeo Katsuki, and Gert Lanckriet. 2017. "Machine Learning to Detect Prescription Opioid Abuse Promotion and Access via Twitter." American Journal of Public Health 107 (12): e1-6. https:// doi.org/10.2105/AJPH.2017.303994.

Martínez-Miranda, Enrique, Peter McBurney, and Matthew J. Howard. 2016. "Learning Unfair Trading: A Market Manipulation Analysis From the Reinforcement Learning Perspective." Proceedings of the 2016 IEEE Conference on Evolving and Adaptive Intelligent Systems, EAIS 2016, 103-9. https://doi.org/10.1109/EAIS.2016.7502499.

McAllister, Amanda. 2017. "Stranger than Science Fiction: The Rise of A.I. Interrogation in the Dawn of Autonomous Robots and the Need for an Additional Protocol to the U.N. Convention Against Torture." Minnesota Law Review 101: 2527-73. https://doi.org/10.3366/ajicl.2011.0005.

McCarthy, John, Marvin L Minsky, Nathaniel Rochester, and Claude E Shannon. 1955. "A Proposal for the Dartmouth Summer Research Project on Artificial Intelligence," August. https://doi.org/10.1609/aimag.v27i4.1904.

Mckelvey, Fenwick, and Elizabeth Dubois. 2017. "Computational Propaganda in Canada: The Use of Political Bots," no. 6: 32.

Meneguzzi, Felipe, and Michael Luck. 2009. "Norm-Based Behaviour Modification in BDI Agents." In Proceedings of the Eighth International Joint Conference on Autonomous Agents and MultiAgent Systems (AAMAS 2009), 177-84.

Moor, James H. 1985. "What Is Computer Ethics?” Metaphilosophy 16 (4).

Neff, Gina, and Peter Nagy. 2016. "Talking to Bots: Symbiotic Agency and the Case of Tay." International Journal of Communication 10: 4915-31.

Nunamaker Jr., Jay F., Douglas C. Derrick, Aaron C. Elkins, Judee K. Burgo, and Mark W. Patto. 2011. "Embodied Conversational Agent-Based Kiosk for Automated Interviewing." Journal of Management Information Systems 28 (1): 17-48.

Office for National Statistics. 2016. "Crime in England and Wales, Year Ending June 2016 Appendix Tables," no. June 2017: 1-60.

"Paedophiles Are Being Caught after They Order Child like Sex Dolls." 2017. The Independent. July 31, 2017. http://www.independent.co.uk/news/uk/crime/paedophiles-uk-arrestschild-sex-dolls-lifelike-border-officers-aids-silicone-amazon-ebay-online-ncaa7868686.html.

Pagallo, Ugo. 2011. "Killers, Fridges, and Slaves: A Legal Journey in Robotics." AI and Society 26 (4): 347-54. https://doi.org/10.1007/s00146-010-0316-0. 
2017a. "From Automation to Autonomous Systems: A Legal Phenomenology with Problems of Accountability." In Proceedings of the Twenty-Sixth International Joint Conference on Artificial Intelligence (IJCAI-17), 17-23.

2017b. "When Morals Ain't Enough: Robots, Ethics, and the Rules of the Law." Minds and Machines, 1-14. https://doi.org/10.1007/s11023-017-9418-5.

Poel, Ibo van de, Jessica Nihlén Fahlquist, Neelke Doorn, Sjoerd Zwart, and Lambèr Royakkers. 2012. "The Problem of Many Hands: Climate Change as an Example." Science and Engineering Ethics 18: 49-67.

Ratkiewicz, Jacob, Michael Conover, Mark Meiss, Bruno Gonçalves, Snehal Patil, Alessandro Flammini, and Filippo Menczer. 2011. "Truthy: Mapping the Spread of Astroturf in Microblog Streams." Proceedings of the 20th International Conference Companion on World Wide $W e b(W W W$ '11), 249-52. https:// doi.org/10.1145/1963192.1963301.

Rehm, Matthias. 2008. "'She Is Just Stupid'-Analyzing User-Agent Interactions in Emotional Game Situations." Interacting with Computers 20 (3): 311-25. https://doi.org/10.1016/j.intcom.2008.02.005.

Riemsdijk, M. Birna van, Louise A Dennis, Michael Fisher, and Koen V. Hindriks. 2013. "Agent Reasoning for Norm Compliance A Semantic Approach." In Proceedings of the 12th International Conference on Autonomous Agents and Multiagent Systems (AAMAS 2013), 499-506. Saint Paul, Minnesota, USA.

Riemsdijk, M Birna Van, Louise Dennis, and Michael Fisher. 2015. "A Semantic Framework for Socially Adaptive Agents Towards Strong Norm Compliance." Proceedings of the 14th International Conference on Autonomous Agents and Multiagent Systems (AAMAS 2015), 423-32.

Sxtenes, Geir Marius. 2017. "Manipulation and Deception with Social Bots: Strategies and Indicators for Minimizing Impact," no. May.

Searle, John R. 1983. Intentionality: An Essay in the Philosophy of Mind. Cambridge university press.

Seymour, John, and Philip Tully. 2016. "Weaponizing Data Science for Social Engineering: Automated E2E Spear Phishing on Twitter.” In .

Sharkey, Noel, Marc Goodman, and Nick Ross. 2010. “The Coming Robot Crime Wave." IEEE Computer Magazine 43 (8).

Solis, Gary D. 2016. The Law of Armed Conflict: International Humanitarian Law in War. Vol. 2nd Edition.

Spatt, Chester. 2014. "Security Market Manipulation." Annual Review of Financial Economics 6 (1): 405-18. https://doi.org/10.1146/annurev-financial-110613-034232.

Taddeo, Mariarosaria. 2017. "Deterrence by Norms to Stop Interstate Cyber Attacks." Minds and Machines, no. September: 10-15. https://doi.org/10.1007/s11023-017-9446-1.

Taddeo, Mariarosaria, and Luciano Floridi. 2005. "Solving the Symbol Grounding Problem: A Criticial Review of Fifteen Years of Research.” Journal of Experimental and Theoretical Artificial Intelligence.

Tonti, Gianluca, JM Bradshaw, and Renia Jeffers. 2003. "Semantic Web Languages for Policy Representation and Reasoning: A Comparison of KAoS, Rei, and Ponder." In In Proceedings of International Semantic Web Conference, 419-37.

Tony Marrero. 2016. "Record Pacific Cocaine Haul Brings Hundreds of Cases to Tampa Court." Tampa Bay Times, September 10, 2016.

“Twitter - Impersonation Policy.” 2018. Twitter. 2018. https://help.twitter.com/en/rules-andpolicies/twitter-impersonation-policy.

Uszok, A, J Bradshaw, R Jeffers, N Suri, P Hayes, M Breedy, L Bunch, M Johnson, S Kulkarni, and J Lott. 2003. "KAoS Policy and Domain Services: Toward a Description-Logic Approach to Policy Representation, Deconfliction, and Enforcement." In Proceedings of IEEE Policy 2003, 93-98. Los Amitos, CA: IEEE Computer Society. 
Vanderelst, Dieter, and Alan Winfield. 2016a. "An Architecture for Ethical Robots Inspired by the Simulation Theory of Cognition." Cognitive Systems Research, 1-15. https://doi.org/10.1016/j.cogsys.2017.04.002. . 2016b. "The Dark Side of Ethical Robots," no. 1: 1-6.

Veletsianos, George, Cassandra Scharber, and Aaron Doering. 2008. "When Sex, Drugs, and Violence Enter the Classroom: Conversations between Adolescents and a Female Pedagogical Agent." Interacting with Computers 20 (3): 292-301. https://doi.org/10.1016/j.intcom.2008.02.007.

Wang, Gang, Manish Mohanlal, Christo Wilson, Xiao Wang, Miriam Metzger, Haitao Zheng, and Ben Y. Zhao. 2012. "Social Turing Tests: Crowdsourcing Sybil Detection." http://arxiv.org/abs/1205.3856.

Wang, Yilun, and Michal Kosinski. 2017. "Deep Neural Networks Can Detect Sexual Orientation from Faces." Journal of Personality and Social Psychology, 1-47.

Weizenbaum, Joseph. 1976. Computer Power and Human Reason: From Judgment to Calculation. Oxford: W. H. Freeman \& Co.

Wellman, Michael P, and Uday Rajan. 2017. "Ethical Issues for Autonomous Trading Agents." Minds and Machines 27 (4): 609-24.

Whitby, Blay. 2008. "Sometimes It's Hard to Be a Robot: A Call for Action on the Ethics of Abusing Artificial Agents." Interacting with Computers.

Williams, Rebecca. 2017. "Lords Select Committee, Artificial Intelligence Committee, Written Evidence

(AIC0206)." http://data.parliament.uk/writtenevidence/committeeevidence.svc/evidencedocument/ artificial-intelligence-committee/artificial-intelligence/written/70496.html\#_ftn13.

Yang, Guang-Zhong, Jim Bellingham, Pierre E. Dupont, Peer Fischer, Luciano Floridi, Robert Full, Neil Jacobstein, et al. 2018. "The Grand Challenges of Science Robotics." Science Robotics 3 (14): eaar7650. https://doi.org/10.1126/scirobotics.aar7650.

Zhou, Wei, and Gaurav Kapoor. 2011. "Detecting Evolutionary Financial Statement Fraud." Decision Support Systems 50 (3): 570-75. https://doi.org/10.1016/j.dss.2010.08.007. 